\title{
SELECTED SUMMARY
}

\section{Somatostatin analogue and small bowel fistula output}

Blind evaluation of the effect of Oreotide (SMS 201. 995), a somatostatin analogue, on small bowel fistula output. Nubiola-Calong P, Badia JM, Sancho J, Gil MJ, Sergura M, Sitges-Serra A. Lancet 1987;ii:672-3.

T he effect of a somatostatin analogue on small bowel fistula output was studied in a blind crossover study.

The study involved 14 patients with postoperative fistulae which had persisted for at least seven days and did not originate in cancerous or ischemic bowel. Conservative treatment; parenteral nutrition, cimetidine and nasogastric suction, had been used on all patients.

The patients were divided into two groups, one received somatostatin analogue, 75 to $100 \mu$ g every $8 \mathrm{~h}$ subcutaneously, for two days and then placebo, while the other received placebo and then the analogue. All patients continued to receive somatostatin analogue after the four-day crossover trial.

Fistulae closed spontaneously in 11 patients in two to 10 days. Three of five patients with high output fistulae with large anatomical defects required surgical treatment because their fistulae did not close. Two of these patients died of persistent intra-abdominal infection. Two patients had an anastomotic dehiscence and distal obstruction. One patient, who had received natural somatostatin, had an allergic reaction to the analogue.

The authors note that the reduction of fistulae output was similar to that obtained with parenteral nutrition alone, however, the average time to fistula closure was much less, 4.5 as opposed to 30 to 40 days.

Therefore, somatostatin analogue may be a useful adjunctive therapy in treatment of postoperative enterocutaneous fistula of the small bowel if they are low volume. High volume enterocutaneous fistulae do not heal well, and anastomotic dihiscence can lead to persistent intra-abdominal infection and death.

Despite parenteral nutrition and somatostatin analogue, clinical judgement is crucial in the management of these patients and some benefit may ensue from early surgical exploration.

STEPHEN L. WOLMAN, MD, FRCP(C) 


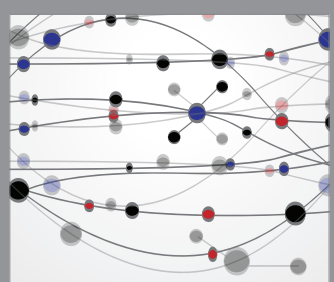

The Scientific World Journal
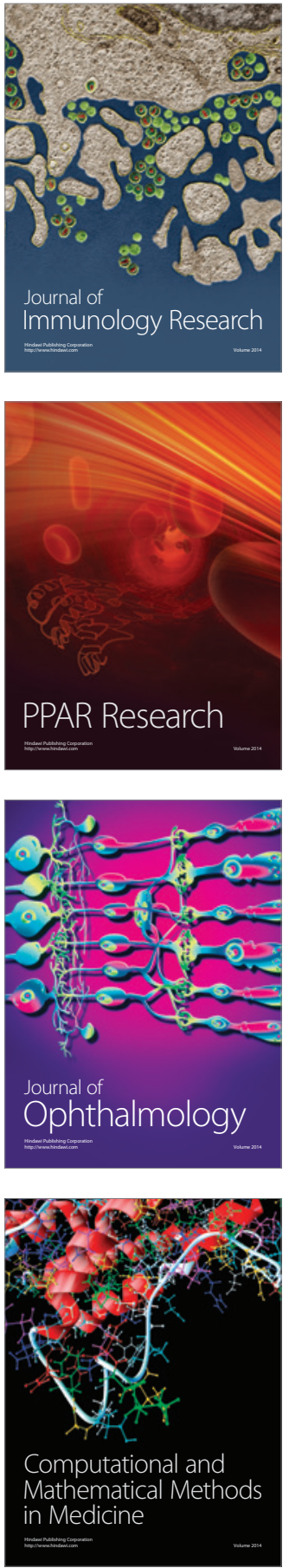

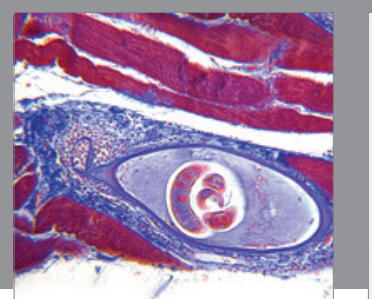

Gastroenterology Research and Practice

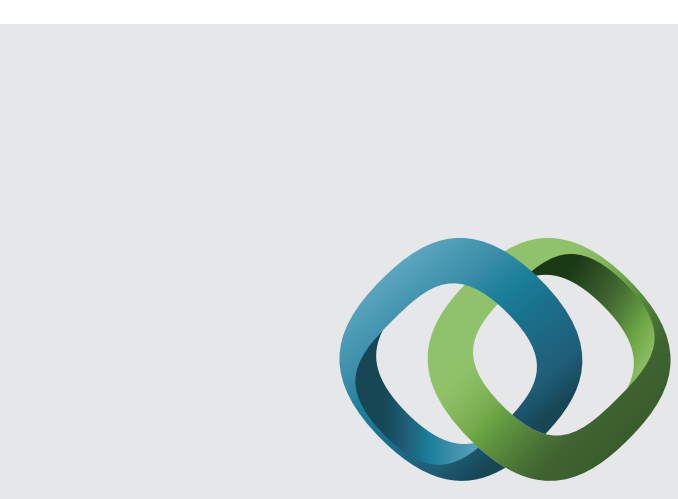

\section{Hindawi}

Submit your manuscripts at

http://www.hindawi.com
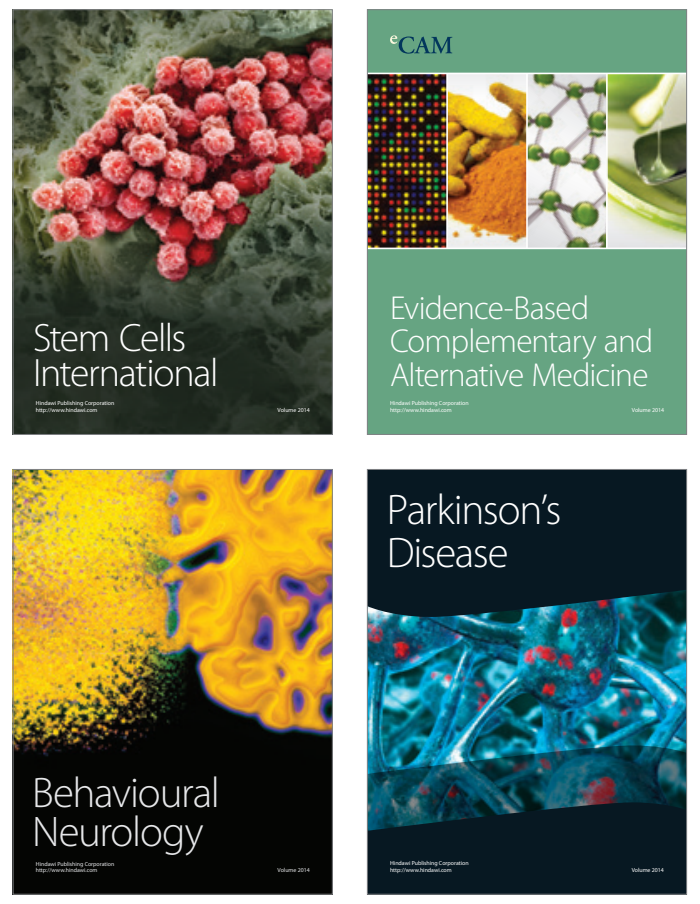
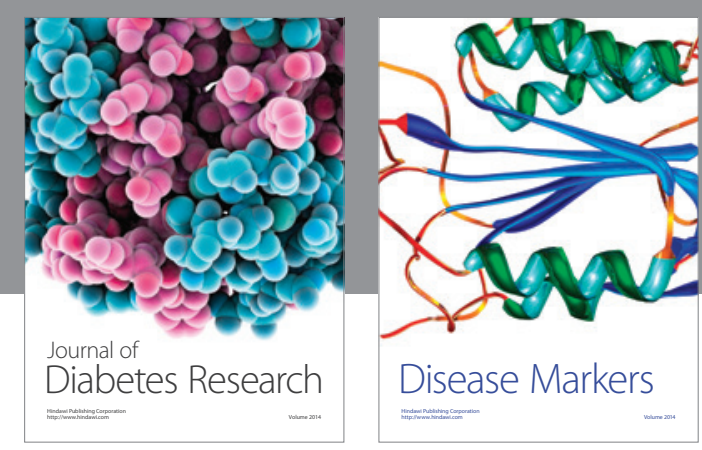

Disease Markers
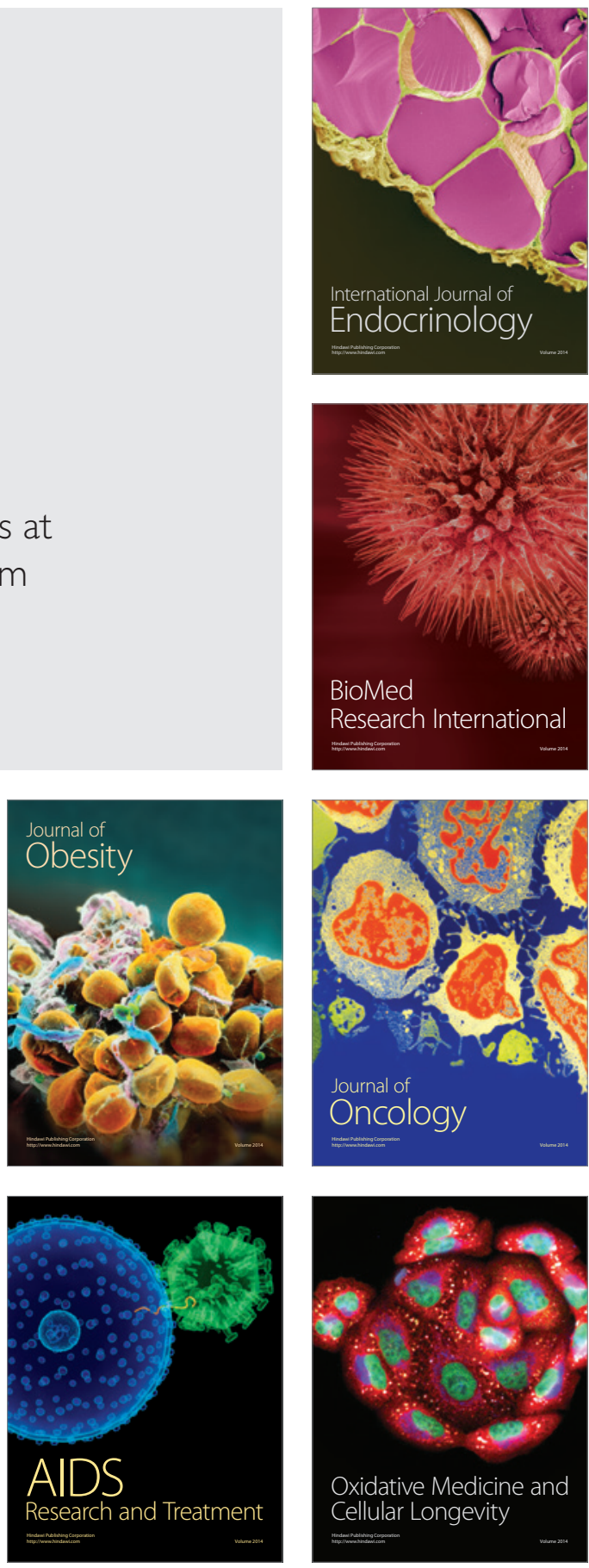